\title{
Book Review: Work, Worklessness and the Political Economy of Health
}

Dec 182011

In her new book Clare Bambra argues that social democratic policies - such as those practiced in Scandinavia - produce better, healthier environments for people to work in, and that we need to 'think big' if we want to see a change in the UK. Daniel Sage believes Bambra's work will serve policy-makers and students well, as it explores the complex structural relationships between work, worklessness and population health.

\section{Work, Worklessness and the Political Economy of Health. Clare Bambra. Oxford University Press. October 2011.}

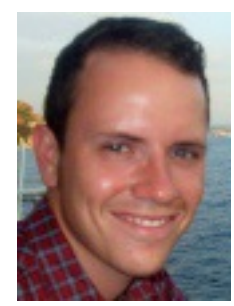

In recent decades, researchers working in public health and epidemiology have become increasingly interested in the social and economic determinants of population health. While most evidence tends to be dichotomised between material and psychosocial explanations (such as income and social cohesion, respectively), this new book by Clare Bambra - Professor of Public Health Policy at Durham University - explores all of these factors within the wider context of work. It is work, she argues, that is the central determinant of health inequalities.

The main meat of Bambra's argument focuses on outlining the evidence base of how work (and of course worklessness) affects population health and wellbeing. This encompasses a wide range of areas, such as physical working conditions, the psychosocial work environment, the experience of unemployment, the role of welfare state provisions and the impact of illhealth on long-term exclusion from the labour market. All in all, Bambra argues that the evidence shows how work is perhaps the most important variable in determining a population's health.

This review leads Bambra to perhaps her most important point: a riposte to what she sees as more individualised (and stigmatising) accounts of

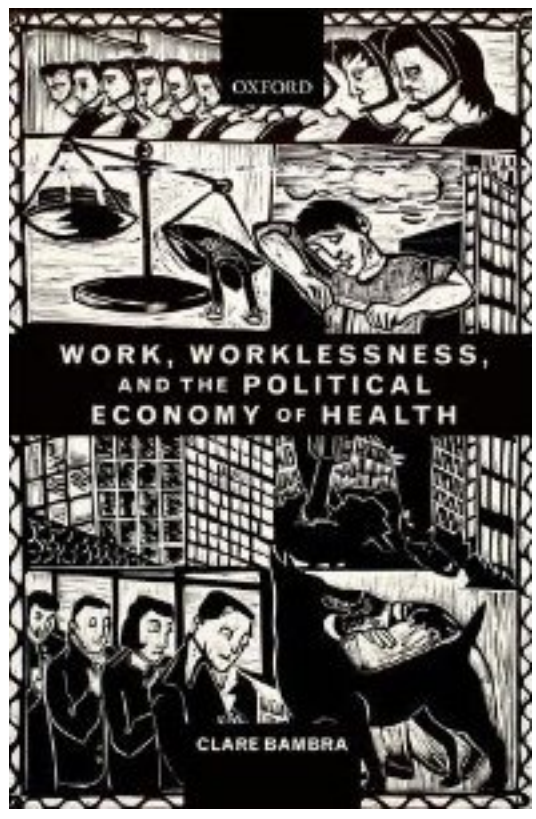
work, unemployment and health. To individualise these issues is a profound mistake she argues: the evidence outlines how the impact of work on health varies and is mediated across different welfare states. Thus, what matters are the political and economic structures that interact with a population's experience of work and worklessness and, consequently, the effect these have on health inequalities. All in all, Bambra argues that social democratic policies - such as those practiced in Scandinavia - produce better, healthier environments for people to work (and be workless) in.

Bambra's conclusion is a conceptualisation of a 'model of the political economy of health inequalities'. In the model, Bambra argues that a government can intervene to redress work-related health inequalities at three different levels: the macro (the economy, the state and social security), the meso (the work environment) and the micro (the individual). The first two levels refer to the causes of health problems, while the third level of the individual is where policies can merely treat the symptoms.

There are some important implications here for policy-makers. In short, if we really want to improve population health, Bambra's thesis suggests that we need to act big: or, in her words, to have a strategy of 'macro primary prevention policy intervention'. This would involve policies like the provision of a minimum income, better job security and reductions in income inequality: all of which would have the effect of fundamentally restructuring the economic system. This argument exposes the potential limitations of existing approaches, most of which intervene at the individual, 'treatment' level. While such policies (such as personal assistance and job-seeking help) may be politically easy, they have a high cost in the long-term; the evidence outlined by Bambra shows they have an extremely modest effect on the problems they purport to solve.

While Bambra's broad argument might be convincing and rigorous, there are times however when the book reads like an extended literature review rather than a new and innovative thesis in itself. Bambra states that the book adopts a 'political economy approach', yet she spends so much time reviewing vast swathes of 
evidence that the central thread of her argument is often diluted; thus, it becomes easy to be detracted from the argument Bambra seeks to construct. There is such a wide range of theories drawn upon - from material to psychosocial and Marxist to New Right - that is sometimes difficult to work out what Bambra's own argument really is.

This is perhaps indicative of the feeling that Work, Worklessness and the Political Economy of Health falls short of offering anything genuinely new to existing debates about the relationship of work and worklessness to population health. The central argument of the book - that political, economic and social factors are the most important in explaining the relationship between work and ill-health - does not seem exceptionally revelatory. Nevertheless, the evidence base explored by Bambra is extraordinarily deep and varied and includes insights from economics, epidemiology, sociology and political science. It will surely serve as an excellent guide for students in the social sciences with interests in work and health. Further, it may also serve - perhaps even more usefully - as a guide to politicians and policy-makers; many of whom too often appear to take a narrow, individualised approach to what are, as Bambra shows, the complex and structural relationships between work, worklessness and population health.

\section{Work, Worklessness and the Political Economy of Health. Clare Bambra. Oxford University Press.} October 2011.

\section{Find this book: Google Books Amazon}

This entry was posted in British Politics and Policy, Daniel Sage, Political Theory and tagged health policy, income, labour market, population, public health, Scandinavia, unemployment, welfare state, $\underline{\text { work}}$, worklessness. 